\title{
Política Nacional de Resíduos Sólidos: Breve Análise do Legado de uma Década
}

\author{
Jorge Edmir da Silva dos Santos'; Ana Ghislane Henriques Pereira van Elk \\ 凹anavanelk@gmail.com
}

1. Departamento de Engenharia Sanitária e Meio Ambiente - UERJ, Maracanã - RJ.

Histórico do Artigo: 0 autor detém os direitos autorais deste artigo.

Recebido em: 26 de agosto de 2020 Aceito em: 08 de fevereiro de 2021 Publicado em: 31 de agosto de 2021

Resumo: A Política Nacional de Resíduos Sólidos completou a sua primeira década de existência, portanto é relevante que se avalie alguns dos resultados obtidos pela lei. Com esse objetivo, os dados do Panorama dos Resíduos Sólidos no Brasil publicados pela Associação Brasileira de Empresas de Limpeza Urbana e Resíduos Especiais referentes aos anos 2010 e 2018 foram analisados para cada região do país. A breve análise do desempenho dos indicadores selecionados (despesa municipal, geração, coleta, coleta seletiva, logística reversa, consórcios, disposição final e reciclagem) permitiu concluir que a evolução da gestão de resíduos sólidos no período foi discreta. Embora, houve avanços na abrangência da coleta regular e coleta seletiva, encerramento de lixões, aumento da disposição em aterros sanitários, o Brasil continua sendo um dos maiores geradores de resíduos sólidos do mundo e a reciclagem ainda é um grande desafio.

Palavras-chave: Evolução indicadores, ABRELPE, Política nacional de resíduos sólidos, Resíduos sólidos, Diferenças inter-regionais.

\section{National Solid Waste Policy: Brief Analysis of the Legacy of a Decade}

Abstract: The National Solid Waste Policy completed its first decade of existence, so it is relevant to evaluate some of the results obtained by law. For that purpose, the data from the Panorama of Solid Waste in Brazil published by the Brazilian Association of Urban Cleaning and Special Waste Companies for the years 2010 e 2018 were analyzed for each region of the country. The brief analysis of the performance of the selected indicators (municipal expenditure, generation, collection, selective collection, reverse logistic, consortium, final disposal and recycling) allowed us to conclude that the evolution of solid waste management in the period was discreet. Although, there have been advances in the scope of regular collection and selective collection, closure of dumps, disposal in sanitary landfills, Brazil remains one of the largest solid waste generators in the world and recycling is still a great challenge.

Keywords: Indicators evolution, ABRELPE, National solid waste policy, Solid waste, Inter-regional differences. 


\section{Política Nacional de Residuos Sólidos: Breve Análisis del Legado de una Década}

Resumen: La Política Nacional de Residuos Sólidos cumplió su primera década, por lo tanto, es relevante evaluar algunos de los resultados obtenidos por la ley. Para ello, se analizaron los datos del Panorama de Residuos Sólidos en Brasil publicado por la Asociación Brasileña de Empresas de Limpieza Urbana y Residuos Especiales para los años 2010 y 2018 para cada región del país. El breve análisis del desempeño de los indicadores seleccionados (gasto municipal, generación, recolección, recolección selectiva, logística inversa, consorcios, disposición final y reciclaje) permitió concluir que la evolución de la gestión de residuos sólidos en el período fue discreta. Aunque ha habido avances en el alcance de la recolección regular y la recolección selectiva, en la clausura de basureros y construcción de nuevos vertederos, Brasil sigue siendo uno de los mayores generadores de residuos sólidos en el mundo y el reciclaje aún es un gran desafío.

Palabras clave: Evolución indicadores, ABRELPE, Política nacional de residuos sólidos, Residuos sólidos, Diferencias interregionales.

\section{INTRODUÇÃo}

A Política Nacional de Resíduos Sólidos (Lei Federal $n^{0}$ 12.305/2010), aprovada após 20 anos de tramitação no Congresso Nacional, estabeleceu as diretrizes e os instrumentos para a gestão dos resíduos sólidos, trazendo aspectos relevantes e em consonância com as políticas de países desenvolvidos. Com a sua promulgação, os principais conceitos, definições e instrumentos de controle foram oficialmente estabelecidos, norteando programas e projetos no setor de resíduos sólidos no país.

Dentre os instrumentos pelos quais se apoia a Política Nacional de Resíduos Sólidos (PNRS) e que trazem um caráter inovador estão os planos de gestão de resíduos sólidos, que devem ser elaborados em nível nacional, estadual e municipal, o controle social, a logística reversa, a responsabilidade compartilhada, o incentivo à criação de cooperativas de materiais recicláveis, inserindo os catadores nos programas de coleta seletiva, os incentivos fiscais para as indústrias recicladoras e os inventários de carbono. Outros aspectos relevantes são 0 planejamento, a visão sistêmica da gestão de resíduos sólidos, o respeito às diversidades locais e regionais e a hierarquia de resíduos, estabelecendo como prioridades a não geração, a redução na fonte, o reaproveitamento e a reciclagem, tratamento e disposição final dos rejeitos.

Após 10 anos da aplicação da PNRS, houve indubitavelmente avanços na gestão de resíduos sólidos no país, principalmente na formação de consórcios, encerramento de lixões, aumento da coleta seletiva, inserção de catadores no processo de reciclagem e elaboração de planos estaduais e municipais de gestão de resíduos. Não obstante, de acordo com van Elk \& 
Boscov (2016), há ainda um longo caminho a ser percorrido para efetivar a realidade antevista pela Lei.

Autores como Onofre et al:; Silva et al., 2014; Simão et al., 2017; Grisa \& Capanema, 2018, citam como entraves que limitam à implementação da PNRS no Brasil a baixa capacidade técnica e financeira dos municípios, falta de cobrança pela gestão dos serviços de limpeza urbana, descontinuidade administrativa com a troca dos dirigentes e fiscalização deficiente. Já Maiello et al. (2018) destacam a existência de lacunas estruturais entre os principais níveis de governo que formulam as políticas e os reais executores dessas normas e diretrizes.

Dentro dessa perspectiva o presente artigo procura mostrar os resultados alcançados durante essa década, baseando-se nos dados do Panorama dos Resíduos Sólidos no Brasil, elaborado pela Associação Brasileira de Empresas de Limpeza Urbana e Resíduos Especiais (ABRELPE) com o objetivo de analisar a evolução temporal, comparando-se os anos 2010 e 2018 (sempre que possível), de determinados indicadores da gestão de resíduos sólidos aliados a dispositivos presentes na Política Nacional de Resíduos Sólidos, possibilitando uma visão geral do cenário da gestão de resíduos sólidos no país.

\section{MATERIAL E MÉTODOS}

0 presente trabalho trata-se de um estudo exploratório baseado na análise dos relatórios da ABRELPE referentes aos anos 2010 e 2018. Foi realizado um recorte de determinados dispositivos inseridos na PNRS, os quais se destinam a proporcionar a exequibilidade da Lei 12.305/2010, que são:

1- $\quad$ coleta seletiva;

2- reciclagem;

3- logística reversa;

4- $\quad$ erradicação de lixões.

0s relatórios mencionados também serviram como base para analisar importantes aspectos da gestão de resíduos na escala nacional, como despesas municipais com a gestão dos resíduos sólidos urbanos, os índices relativos à geração e a abrangência da coleta regular de resíduos. Complementarmente, os dados sobre consórcios públicos foram coletados no estudo Perfil dos Municípios Brasileiros (IBGE, 2020).

É importante ressaltar que, embora os Panoramas Nacionais de Resíduos Sólidos publicados anualmente pela ABRELPE contemplem informações além das abordadas neste trabalho, esta pesquisa delimitou o campo observado às temáticas descritas acima. 


\section{RESULTADOS E DISCUSSÃ0}

0 indicador referente a despesa municipal per capita com a gestão de RSU consiste na despesa das prefeituras com manejo de Resíduo Sólido Urbano em relação à população urbana e é expresso em reais por habitante.

Embora a análise dos dados mostre que no Brasil houve um aumento correspondente a 2,0\% nas despesas com a gestão dos RSU na comparação entre 2010 e 2018, neste período correspondente, o valor da despesa oscilou, registrando a maior queda entre 2012 e 2013 ( $R \$ 133,56$ e R\$ 114,84, respectivamente). Segundo a ABRELPE (2019), em 2018 a média nacional per capita foi igual a $\mathrm{R} \$ 121,80$ hab./ano. A região Sudeste apresentou uma despesa acima da média, cujo valor foi de $\mathrm{R} \$ 156,36$ por hab./ano.

De acordo com a PricewaterhouseCoopers (PwC, 2014), o valor da despesa per capita das cidades brasileiras são cinco vezes menores do que cidades como Barcelona, Roma e Paris.

Conforme os dados presentes na Tabela 1, o componente demais serviços de limpeza urbana sofreu queda de 1,60\%, enquanto o componente coleta, apresentou um aumento de aproximadamente 8,0\% nas despesas, o que permitiu um valor absoluto positivo do indicador.

Os dados apresentados na Tabela 1 mostram diferenças em relação ao indicador despesa com a gestão dos RSU entre as diferentes regiões do país. Observou-se que o desempenho na região Norte apresentou uma queda expressiva de $16,4 \%$, já na região Sudeste houve um aumento de $13,2 \%$. Este aspecto pode influenciar diretamente no desempenho dos demais indicadores a serem discutidos na região Sudeste.

Para o indicador coleta de RSU, apenas duas regiões (Norte e Nordeste), apresentaram queda nas despesas. Já para o indicador “demais serviços”, as regiões Centro-0este, Sudeste e Sul apresentaram alta.

Tabela 1. Despesa municipal per capita com gestão de RSU no país, em reais por habitante ao mês.

\begin{tabular}{lllllllllll}
\hline & \multirow{2}{*}{ Norte } & & \multicolumn{2}{l}{ Nordeste } & \multicolumn{2}{l}{ Centro- } & \multicolumn{2}{l}{ Sudeste } & \multicolumn{2}{l}{ Sul } \\
& 2010 & 2018 & 2010 & 2018 & 2010 & 2018 & 2010 & 2018 & 2010 & 2018 \\
\hline $\begin{array}{l}\text { Coleta } \\
\text { RSU }\end{array}$ & 3,79 & 3,24 & 3,19 & 3,14 & 3,00 & 3,13 & 4,19 & 5,00 & 3,34 & 3,69 \\
\hline $\begin{array}{l}\text { Demais } \\
\text { serviços }\end{array}$ & 5,97 & 4,92 & 6,22 & 5,38 & 3,26 & 3,29 & 7,32 & 8,03 & 4,54 & 4,33 \\
\hline
\end{tabular}




\begin{tabular}{lllllllllll} 
Total & 9,76 & 8,16 & 9,41 & 8,52 & 6,26 & 6,42 & 11,51 & 13,03 & 7,88 & 8,02 \\
\hline
\end{tabular}
Fonte: Adaptado de ABRELPE (2010; 2019).

Segundo a ABRELPE (2019), foram gerados 79 milhões de toneladas em 2018, contra 60 milhões de toneladas em 2010. Embora a não geração configure como o ponto inicial da gestão adequada de resíduos sólidos, observa-se no país uma tendência no sentido contrário, pois houve um aumento progressivo no período considerado entre os anos 2010 e 2018. A exceção foi em 2016, ano em que houve uma queda pontual no indicador devido à crise econômica no país.

Diante da realidade observada, a PNRS se destaca por apontar alternativas à geração de resíduos, como o beneficiamento e reaproveitamento de resíduos, a compostagem dos resíduos orgânicos, a logística reversa de embalagens e o incentivo à reciclagem. Como consequência direta da redução na geração de resíduos, há a diminuição da disposição incorreta e melhoria da qualidade ambiental, aumentando a vida útil dos aterros sanitários.

0 Gráfico 1 mostra que todas as regiões apresentaram crescimento da geração diária de RSU no país para os anos 2010 e 2018, sendo o maior aumento registrado na região Norte (24,40\%). Os dados permitem concluir que, em termos absolutos, a região Sudeste gera a maior quantidade diária de RSU, quando comparada com as demais regiões, devido ao maior número de habitantes e o seu poder aquisitivo, praticamente o dobro da região Nordeste, que está em segundo lugar.

Gráfico 1. Quantidade de RSU gerada no país (t./dia)

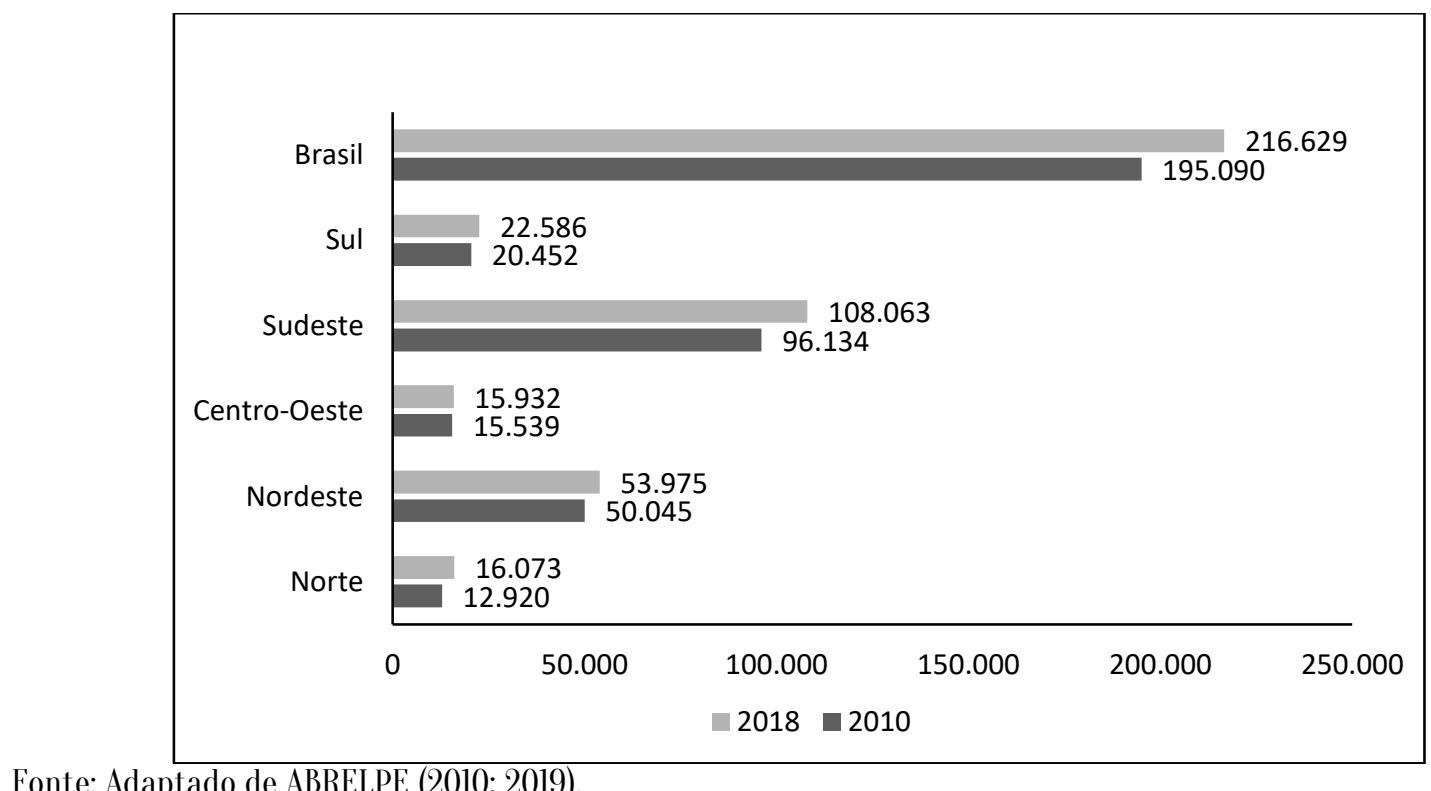

Fonte: Adaptado de ABRELPE (2010; 2019). 
A comparação entre os anos 2010 e 2018 mostra um crescimento médio de cerca de 11\% na geração de RSU no Brasil. A geração per capita teve um aumento de 0,3\% para o mesmo período. Em 2018 a geração per capita foi igual a 1,039 kg/hab./dia.

Luizari (2019) aponta como as principais questões para o aumento da geração dos resíduos sólidos no país o aumento da população e sua concentração nos centros urbanos e da transformação etária da população, cujos costumes estão definidos por práticas de maior consumo, visto o seu maior poder aquisitivo. A autora considera, ainda, o aumento das vendas em função de marketing agressivo, produtos a baixo custo e baixa durabilidade.

Por outro lado, no tocante a coleta de RSU, os dados da ABRELPE demonstraram uma tendência no sentido da universalização do serviço em consonância com o estabelecido na PNRS. Nos anos considerados, o índice médio de cobertura da coleta no país subiu de $89 \%$ para $92 \%$. Segundo a ABRELPE (2019) a região Sudeste, mais uma vez, se destacou com pouco mais de 98\% de cobertura.

De acordo com a Gráfico 2, todas as regiões apresentaram aumento na quantidade de RSU coletada diária. A região com o maior aumento na coleta foi a região Norte com um aumento de 23\%, seguida pelas regiões Sul (15,25\%) e Sudeste (15\%). 0s aumentos observados foram superiores à média nacional que foi igual a 14,8\% no período.

Gráfico 2. Quantidade de RSU coletada no país (t./dia)

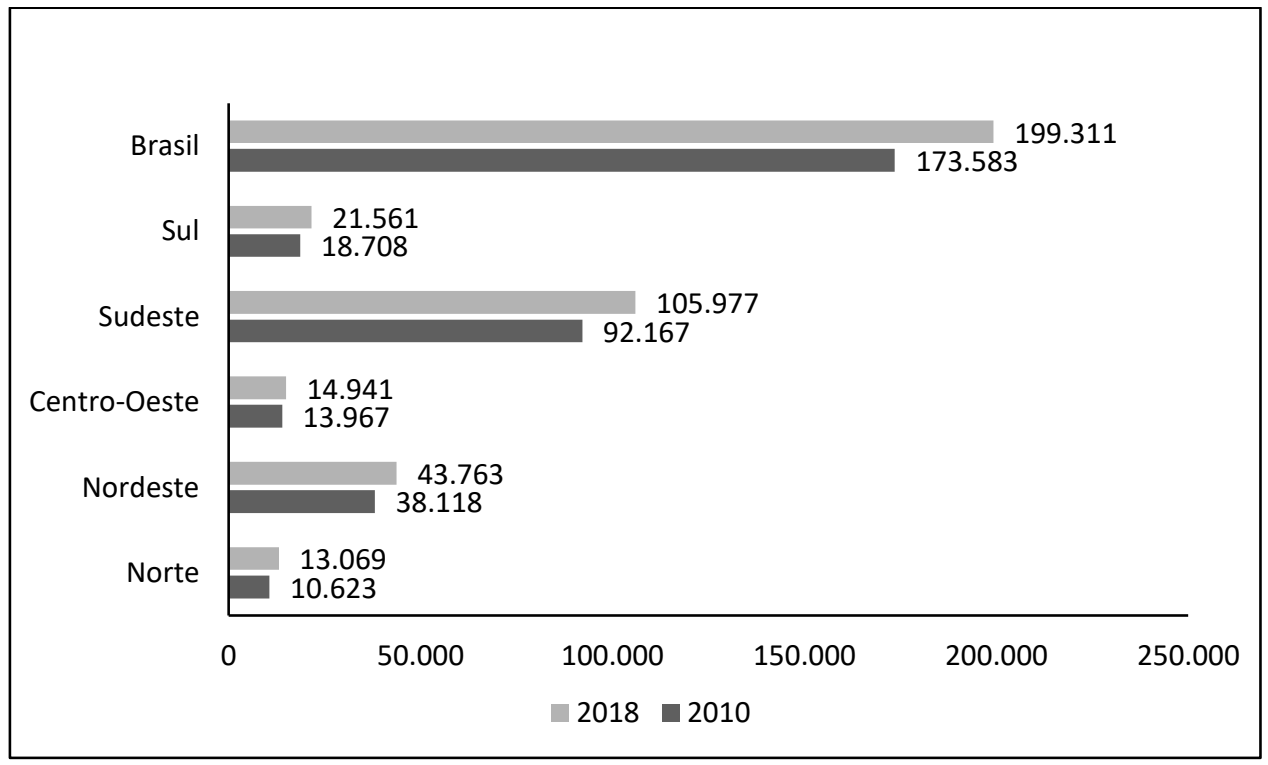

Fonte: Adaptado de ABRELPE (2010; 2019).

Comparando os Gráficos 1 e 2 é possível mensurar a quantidade de resíduos que não foram coletados nos anos 2010 e 2018. A análise dos dados nos mostra que no Brasil, diariamente, 
deixou-se de ser coletados 11,02\% dos resíduos gerados em 2010 e 8\% em 2018. Apenas a região Norte apresentou um aumento na quantidade de resíduos não coletados, de 11,53\% em 2010 para $18,68 \%$ em 2018.

Em relação ao indicador coleta seletiva, Conke e Nascimento (2018) afirmam que a coleta seletiva ainda é incipiente em abrangência e eficiência no país. Dados do CEMPRE (2019) mostram que 1227 municípios brasileiros operavam programas de coleta seletiva em 2018, ou seja, 22\% dos municípios. Tais programas atendiam uma população igual a 35 milhões de habitantes, o que significa que somente 17\% da população têm acesso a programas municipais nesse sentido.

Cabe destacar que a ABRELPE (2019), por sua vez, aponta que, frequentemente, as iniciativas nos municípios resumem-se a ações de disponibilização de Pontos de Entrega Voluntária (PEVs) que não abrangem a totalidade da área urbana.

Quando se compara os anos analisados, observa-se um aumento médio no número de municípios com iniciativas de coleta seletiva, o qual correspondeu a 15,5\% do território nacional, passando de 57,6\% em 2010 para 73,1\% em 2018. Os dados reunidos no Gráfico 3 mostram que todas as regiões apresentaram aumento no número de municípios com tais iniciativas. As regiões Sudeste e Sul se destacam das demais por apresentarem $90 \%$ dos municípios com coleta seletiva em 2018. Já o pior índice pertence à região Centro-0este onde as iniciativas são ausentes em 51,4\% dos municípios.

Gráfico 3. Municípios com iniciativas de coleta seletiva no país (\%).

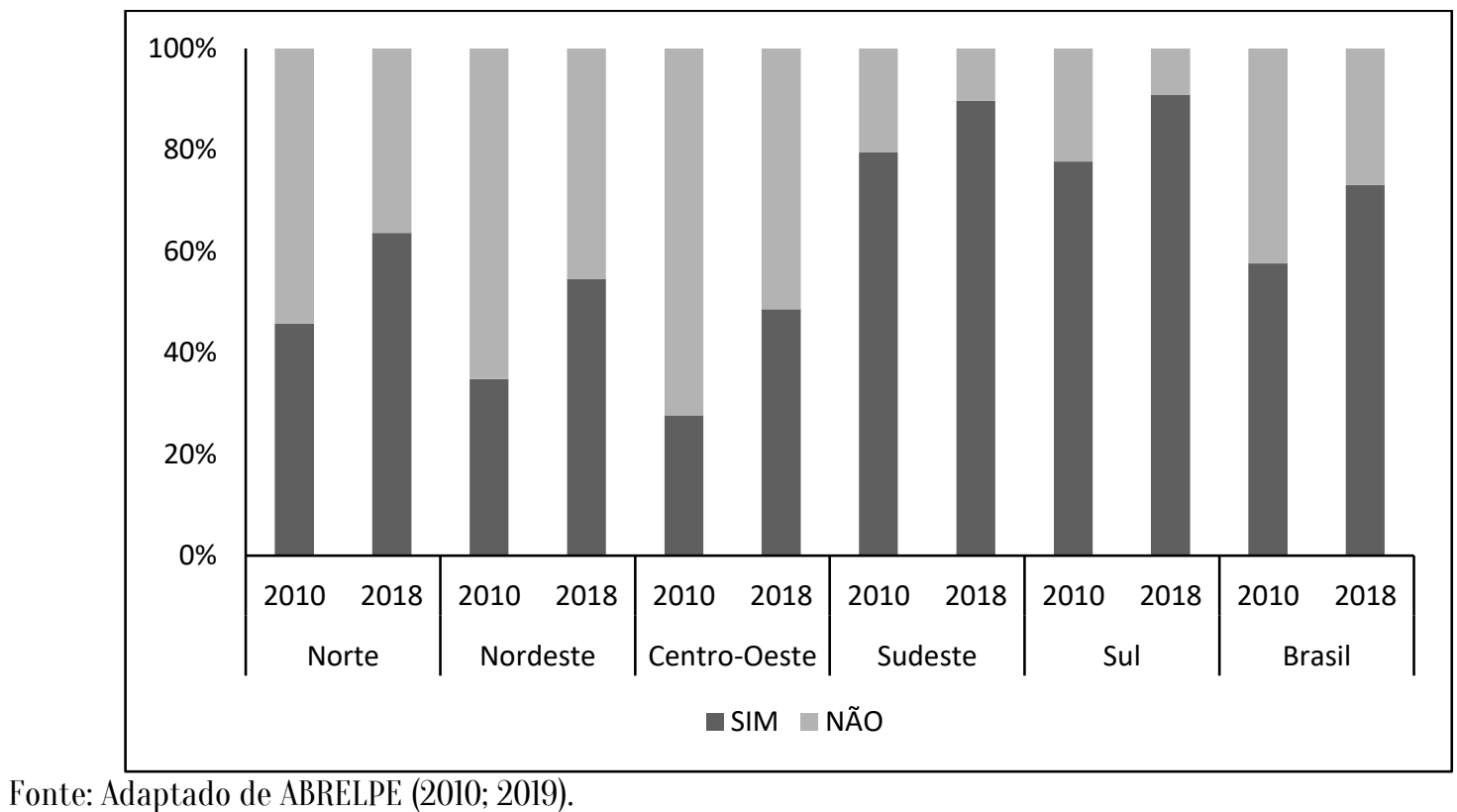


Segundo o CEMPRE (2019), o custo médio da coleta seletiva nas cidades pesquisadas foi de $\mathrm{R} \$ 442,24$ por tonelada. Considerando o valor da coleta regular igual a $\mathrm{R} \$ 95,00$, o custo com a coleta seletiva é 4,6 vezes maior que o custo da coleta convencional.

Quanto à disposição final dos RSU, a meta inicial para a erradicação dos lixões proposta pela PNRS foi o ano 2014 (BRASIL, 2010). No entanto, os prazos foram adiados pela Lei Federal $\mathrm{n}^{\circ}$ 14.026/2020, conhecida como o novo marco legal do saneamento. Além disso, cabe ressaltar que os esforços dos municípios brasileiros para a sua erradicação se concentraram na construção de aterros sanitários como solução adequada.

0s lixões continuam presentes em todas as regiões do país. Em 2010 receberam cerca de 31,5 toneladas de resíduos por dia, já em 2018 esse valor mais que duplicou, alcançando 80 mil toneladas de resíduos por dia, o que significa elevado potencial de poluição ambiental e impactos negativos à saúde.

Conforme indicam os dados apresentados no Gráfico 4, no território brasileiro ocorreu uma redução média de 3,31\% no número de lixões no período considerado. Enquanto os números relacionados ao avanço da construção de aterros sanitários no país, em média, aumentaram 3,29\%. Segundo a ABRELPE (2019) 1.493 municípios ainda utilizam lixões como forma de disposição final no país. Um dos motivos para a dificuldade apresentada pelos municípios para o encerramento é a sua inviabilidade técnica e financeira, muitas vezes somada a falta de comprometimento político.

Todas as regiões reduziram a disposição final em lixões a céu aberto, com exceção da região Centro-0este, onde houve um aumento pouco significativo de $0,2 \%$. No entanto, a região Centro-0este se destaca, entre todas as regiões do país, por apresentar ao fim do período considerado o maior aumento da disposição final em aterros sanitários do país, passando de 28,8\% em 2010 para 41,3\% em 2018, ou seja, 12,5\%. Uma explicação possível para o aumento observado é a assinatura de convênios entre os municípios na busca por soluções compartilhadas para a gestão e manejo dos resíduos sólidos. 
Gráfico 4. Disposição final de RSU no país (\%).

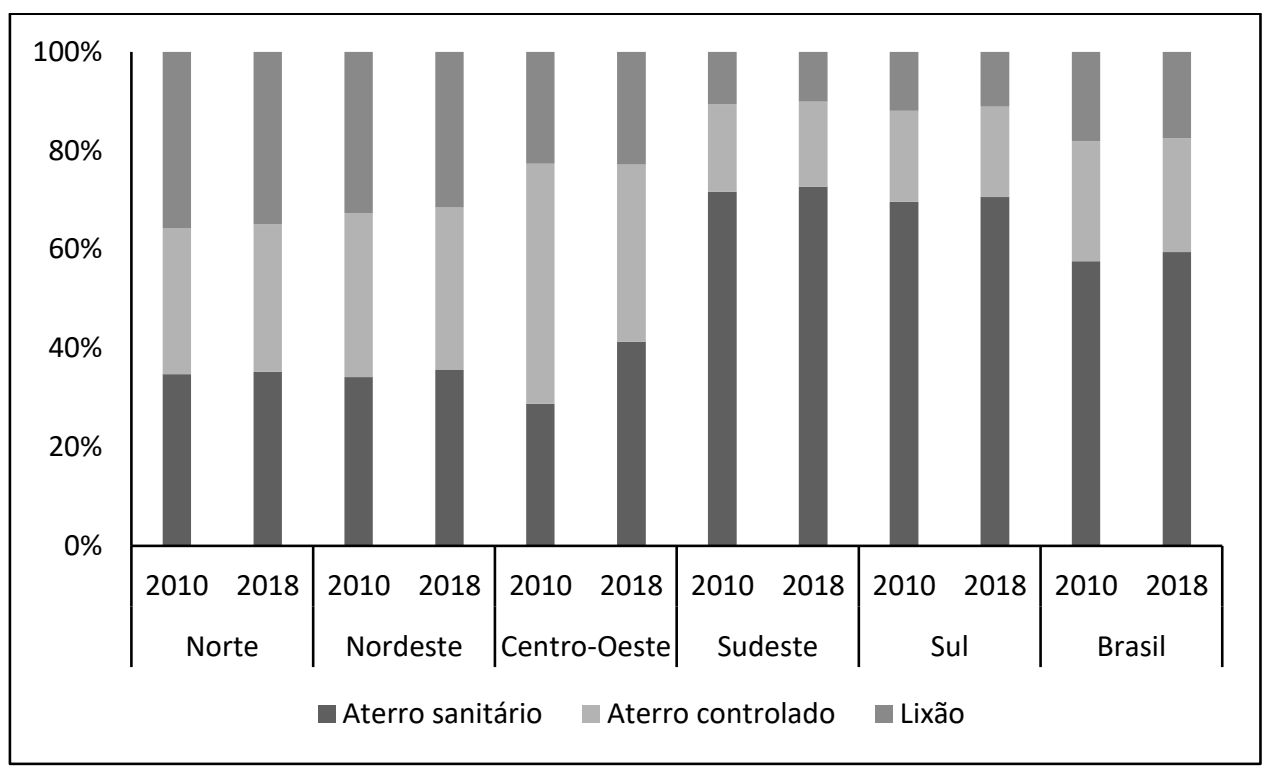

Fonte: Adaptado de ABRELPE (2010; 2019).

Cabe ressaltar que para atender o disposto na PNRS muitos municípios optaram por soluções compartilhadas para a disposição final de resíduos sólidos, aumentando os índices de disposição adequada no país. Assim, um único aterro sanitário atende a vários municípios. № entanto, segundo o IBGE (2020), em 2019 apenas 31,4\% dos municípios brasileiros apresentavam consórcios intermunicipais para o manejo de resíduos sólidos, uma queda de 3,8\% em relação à 2015.

Isso foi possível devido a Lei de Consórcios Públicos (11.107/2005) que dispõe sobre normas gerais para a União, os Estados, o Distrito Federal e os Municípios contratarem esses instrumentos de cooperação para a realização de objetivos de interesse comum. A Lei Federal e o seu regulamento (Decreto n. 6.017/2007) não instituíram os consórcios públicos ou a gestão associada de serviços públicos, pois eles já estavam previstos na Constituição Federal.

0 maior desafio observado foi em relação ao indicador relacionado à reciclagem, segundo o sítio eletrônico da ABRELPE apenas 4\% dos resíduos sólidos produzidos nas cidades brasileiras são reciclados. Dessa forma, o Brasil perde 14 bilhões de reais por ano devido a destinação inadequada.

Cabe ressaltar que o reaproveitamento desse pequeno volume só é viabilizado pelo esforço de catadores, que enfrentam a falta de apoio do poder público e o desconhecimento da população quanto à separação do lixo. 
Em relação aos dados coletados para este indicador, primeiramente, cabe ressaltar que não foi possível a comparação entre os anos de 2010 e 2018, pois as métricas aplicadas nos trabalhos elaborados foram diferentes. Em segundo lugar, cabe esclarecer que os dados ora apresentados no Gráfico 5 se referem aos RSU coletados pelas cooperativas e associações de catadores acompanhadas pela Associação Nacional dos Catadores e Catadoras de Materiais Recicláveis (ANCAT) não refletindo a totalidade do setor de reciclagem no país.

Assim, os dados mostrados no Gráfico 5 permitem concluir, de maneira geral, que materiais como papel, plástico, vidro e metais ainda correspondem ao material reciclável coletado prioritariamente pelas organizações do país para destinação a reciclagem. A matéria orgânica, embora corresponda a maior fração na composição do RSU, possui uma recuperação totalmente insignificante. Mesmo com a implementação da Logística Reversa não foi observada diversificação dos resíduos destinados a recuperação, possivelmente pela baixa participação dessas organizações no processo.

Gráfico 5. Volume de materiais recicláveis coletados no país em 2018 (t./ano).

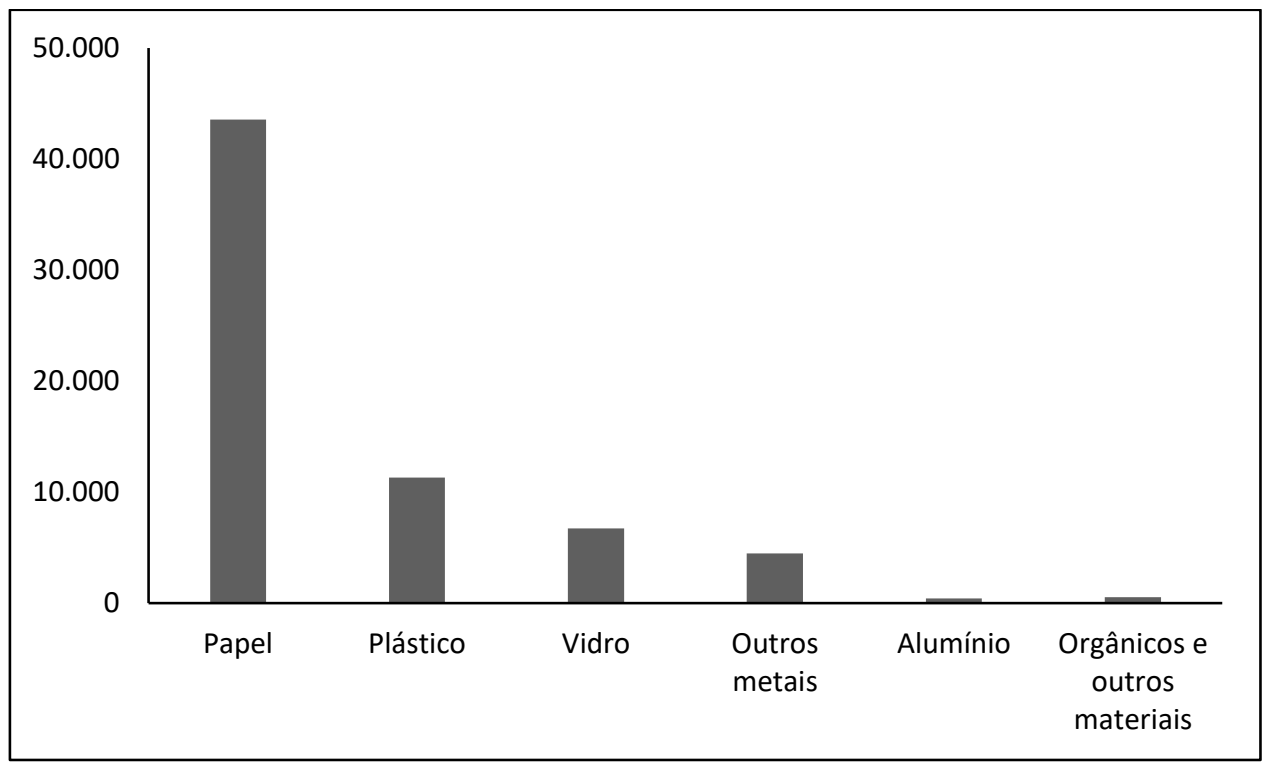

Fonte: Adaptado de ABRELPE (2019).

Em relação à logística reversa, que consiste em um conjunto de ações, procedimentos e meios destinados a viabilizar a coleta e a restituição dos resíduos sólidos ao setor empresarial (BRASIL, 2010). São obrigados a estruturar e implementar sistemas de logística reversa, mediante retorno dos produtos, após o uso pelo consumidor, os fabricantes, importadores, distribuidores e comerciantes de: agrotóxicos, seus resíduos e embalagens; pilhas e baterias; pneus; óleos lubrificantes, seus resíduos e embalagens; lâmpadas fluorescentes, de vapor de 
sódio e mercúrio e de luz mista; produtos eletroeletrônicos e seus componentes e embalagens em geral.

De acordo com Silva (2020), a responsabilidade que apenas o setor privado tem na Europa, no Brasil é dividida entre o fabricante e os demais participantes da cadeia. Desta forma, os agentes públicos acabam atribuindo a si uma responsabilidade que é dos fabricantes, importadores e distribuidores.

A comparação dos dados referentes aos anos 2010 e 2018 não foi possível pois a ABRELPE não apresentou dados em 2010, tendo em vista o ano em que a PNRS foi aprovada. Em relação às embalagens de defensivos agrícolas e de óleo lubrificantes, a ABRELPE (2019) destaca que o Brasil pode ser considerado referência mundial no assunto e que tiveram destino ambientalmente adequado 94\% e 98\% das embalagens após o consumo, respectivamente.

Os dados da ABRELPE (2019) relacionados a logística reversa de pneus inservíveis e lâmpadas não contemplam o ano de 2018. Entretanto, comparando-se 2010 e 2017 observa-se um aumento de 146 mil t. no número de pneus coletados e corretamente destinados no período. Além disso, o número de pontos de coleta aumentou 20 vezes desde 2004 . Em relação às lâmpadas, informa-se que a efetiva implementação desta cadeia ocorreu no ano 2017. Neste ano existiam 304 pontos de coleta instalados no Brasil, responsáveis pela coleta e destinação adequada de $44 \mathrm{t}$.

0 panorama da ABRELPE (2019) não apresenta dados para pilhas e baterias e produtos eletrônicos. Além disso, cabe ressaltar que a proposta de acordo setorial para a implementação da logística reversa de produtos eletroeletrônicos, a criação do decreto para a implementação do sistema para medicamentos descartados e o Termo de Compromisso para embalagens em geral já passaram por consulta pública.

\section{CONCLUSÃO}

A análise da evolução dos dados da ABRELPE para os anos 2010 e 2018 permitiu avaliar, no âmbito da delimitação dos instrumentos da Política Nacional de Resíduos Sólidos, o cenário atual da gestão de resíduos no Brasil. Assim, foram avaliados os seguintes indicadores: despesas municipais, geração e coleta regular de resíduos, logística reversa, formas de disposição final, consórcios públicos, coleta seletiva e reciclagem.

Inicialmente, observa-se a existência de uma disparidade na escala regional, destacando-se com os melhores desempenhos o eixo Sul-Sudeste. 
A taxa de geração de resíduos sólidos urbanos aumentou progressivamente em todo país, contrariamente à hierarquia proposta no gerenciamento dos resíduos sólidos pela política nacional. 0 indicador que apresentou o melhor desempenho em todas as regiões do país foi a coleta regular, a média da cobertura da coleta foi de $92 \%$. No entanto, embora o país caminhe em direção à universalização do serviço de coleta, o serviço deve ser melhorado nas áreas rurais e aglomerados subnormais.

Os lixões significam um problema que não foi resolvido totalmente, não obstante houve um aumento no encerramento de lixões e na disposição final adequada.

0 indicador referente à coleta seletiva no Brasil foi o que apresentou o maior crescimento médio absoluto (26,9\%). Porém, o crescimento observado pode confundir a realidade, uma vez que se refere às iniciativas de coleta seletiva. A questão é que a coleta seletiva ainda é incipiente no país e esse fato compromete à reciclagem. Os níveis de reciclagem pouco avançaram após a aprovação da política nacional no país e observam-se dificuldades na reciclagem dos materiais que não são economicamente viáveis e em um certo descaso no tratamento da matéria orgânica, predominante na composição dos RSU no Brasil. Desta forma, o objetivo de reduzir a quantidade de resíduos sólidos e aumentar a de rejeitos dispostos em aterros sanitários é mais uma das metas a serem alcançadas.

Embora as cadeias de logística reversa de produtos como embalagens de óleos lubrificantes e defensivos agrícolas estejam bem estruturadas e sirvam de modelo, a logística reversa ainda está longe de ser uma realidade, sobretudo pela resistência do setor industrial em internalizar os custos do sistema.

Por fim, as despesas municipais empenhadas na gestão dos resíduos sólidos urbanos frequentemente são ínfimas, provendo somente o mínimo necessário e dificultando avanços no setor, tendo em vista a necessidade de infraestrutura, maquinários e pessoal para que se obtenha bons resultados. 0s valores para a execução de programas e ações muitas vezes ultrapassam o orçamento dos municípios se forem executados com recursos exclusivos da arrecadação local.

A breve análise permitiu concluir que os municípios possuem realidades distintas, em razão das diferenças regionais no desempenho dos indicadores. Os avanços proporcionados pela política nacional na gestão dos resíduos sólidos foram lentos, porém serviram para tirar o país da estagnação que existia no setor. Para que a Política Nacional de Resíduos Sólidos obtenha os resultados esperados é indispensável a realização de articulações em diferentes níveis e o maior comprometimento dos atores envolvidos. 


\section{REFERÊNCIAS BIBLIOGRÁFICAS}

ASSOCIAÇÃO BRASILEIRA DE EMPRESAS DE LIMPEZA PÚBLICA E RESÍDUOS ESPECIAIS (ABRELPE). Panorama dos Resíduos Sólidos no Brasil 2010. 202 p. São Paulo, 2010. Disponível em: https://abrelpe.org.br/download-panorama2010/. Acesso em 10 mar. 2020.

Panorama dos resíduos sólidos no Brasil 2018/2019. 68 p. São Paulo, 2019. Disponível em: http://abrelpe.org.br/download-panorama-2018-2019/. Acesso 10 mar. 2020.

BRASIL. Lei $\mathrm{n}^{0}$ 11.107, de 06 de abril de 2005. Dispõe sobre normas gerais de contratação de consórcios públicos e dá outras providências. Brasília, 06 abr. 2005.

Decreto $\mathrm{n}^{\circ}$ 6.017, de 17 de janeiro de 2007. Regulamenta a Lei $\mathrm{n}^{0} 11.107$, de 6 de abril de 2005, que dispõe sobre normas gerais de contratação de consórcios públicos. Brasília, 17 jan. 2007.

Lei $\mathrm{n}^{0}$ 12.305, de 02 de agosto de 2010. Institui a Política Nacional de Resíduos Sólidos; altera a Lei no 9.605, de 12 de fevereiro de 1998; e dá outras providências. Brasília, 02 ago. 2010.

Lei $\mathrm{n}^{0}$ 14.026, de 15 de julho de 2020. Atualiza o marco legal do saneamento básico [...]. Brasília, 16 jul. 2020.

COMPROMISSO EMPRESARIAL PEARA RECICLAGEM (CEMPRE). Pesquisa Ciclosoft 2018: Radiografando a Coleta

Seletiva. $24 \quad$ p. $\quad$ São $\quad$ Paulo: $\quad$ CEMPRE, $2019 . \quad$ Disponível em:
http://www.ativgreen.com.br/cempre/pesquisa_ciclosoft_2018.pdf. Acesso em: 08 dez. 2020.

CONKE, L. S.; NASCIMENTO, E. P. A coleta seletiva nas pesquisas brasileiras: uma avaliação metodológica. URBE Revista Brasileira de Gestão Urbana (Brazilian Journal of Urban Management), v.10, n.1, p.199-212, 2018.

GRISA, D. C.; CAPANEMA, L. Resíduos Sólidos Urbanos. In: PUGA, F.; CASTRO, L. B. (Orgs.). Visão 2035: Brasil, país desenvolvido: agendas setoriais para alcance da meta. Rio de Janeiro: BNDES, 2018. p. 415-438. Disponível em: https://web.bndes.gov.br/bib/jspui/bitstream/1408/16040/3/PRLiv214078_Visao_2035_compl_P.pdf. Acesso em 17 jun. 2020 .

INSTITUTO BRASILEIRO DE GEOGRAFIA E ESTATÍSTICA (IBGE). Perfil dos municípios brasileiros: 2019. 90 p. Rio de Janeiro: IBGE, 2020. Disponível em: https://biblioteca.ibge.gov.br/visualizacao/livros/livl01770.pdf. Acesso em: 09 dez. 2020.

LUIZARI, J.D. Análise da geração e composição dos resíduos sólidos domiciliares: estudo de caso no Plano Piloto $\begin{array}{lllll}\text { DF. } & 87 & \text { p. } & 2019 . & \text { Disponível }\end{array}$ https://bdm.unb.br/bitstream/10483/24638/1/2019_JanainaDominguesLuizari_tcc.pdf.Acesso em: 09 dez. 2020.

MAIELLO, A., BRITTO, A.L.N.P., VALLE, T.F. Implementação da Política Nacional de Resíduos Sólidos. Revista de Administração Pública FGV, v.52, n.1, p.24-51, 2018.

ONOFRE, Y. S.; PEREIRA, M. P.; BOTELHO, M. I. V. Adequação dos municípios de pequeno porte à lei da Política Nacional de Resíduos Sólidos (PNRS): um estudo em cinco municípios mineiros (Barbacena, Antonio Carlos, Ibertioga, Juiz de Fora e Santos Dumont). In: CONGRESSO BRASILEIR0 DE GESTÃo AMBIENTAL, IBEAS, 5., Belo Horizonte, MG, 2014.

PRICEWATERCOOPERS (PwC). Três anos após a regulamentação da Política Nacional de Resíduos Sólidos (PNRS): seus gargalos e superações. 83 p. São Paulo, 2014 . Disponível em: https://www.pwc.com.br/pt/publicacoes/servicos/assets/consultoria-negocios/estudo-selur-14.pdf.Acesso em 10 mar. 2020. 
SILVA, C. L.; FUGII, G. M.; SANTOYO, A. H.; BASSI, N. S.; VASCONCELOS, M. C. Gestão de resíduos sólidos urbanos em capitais brasileiras alternativas para um modelo de gestão. Revista Brasileira de Ciências Ambientais, n.33, p.118$132,2014$.

SILVA, L. F. Logística reversa de embalagens em geral pós-consumo: panorama atual e análise da implementação do sistema no Brasil. 2020, 87f. Dissertação (mestrado) - Programa de Pós-graduação em Engenharia Ambiental, departamento de Engenharia Sanitária e do Meio Ambiente, UERJ.

SIMÃO, N. M.; DALMO, F. C.; NEBRA, S. A.; SANT’ANA P. H. M. A Política Nacional de Resíduos Sólidos e a estratégia de formação de consórcios públicos intermunicipais. Revista Políticas Públicas, v.21, n.2, p.891-913, 2017.

VAN ELK, A. G. H. P., BOSCOV, M. E. G. Desafios geotécnicos advindos da Política Nacional de Resíduos Sólidos. In: CONGRESSO BRASILEIRO DE MECÂNICA DOS SOLOS E ENGENHARIA GEOTÉCNICA,18., Belo Horizonte, MG, 2016. 